\title{
Revisiting Rosenblatt's Transactional Approach Through Shaun Tan's The Red Tree
}

\author{
Anisha Koshy \\ Department of English, University of Delhi, T-591, Baljit Nagar, Delhi-08, India
}

\begin{abstract}
Readers interpret the meaning from the text in many different manners and Loise Rosenblatt put forward the transactional approach to reading which holds true that reading is more of a transaction between the reader and the text. This theory comes under the umbrella term of Reader Response Criticism. The Red Tree is a children's picture-book by Shaun Tan. He is an Australian artist, film-maker and a writer as well. This paper tries to interpret The Red Tree using the Transactional Approach to understand whether reading can actually be a transaction instead of being totally passive.
\end{abstract}

Keywords: Reader Response, Transactional approach, Picture-book, Interaction

DOI: $10.7176 / \mathrm{JLLL} / 55-02$

Publication date: April $30^{\text {th }} 2019$

\section{Introduction}

Reading is a very complex as well as a dynamic process which can't be described simply in words as the whole process of perception and then the sense-making is quite difficult to explain. Many scholars have put forward various theories or concepts to explain or to describe this process or to promote a particular way to go about it. These concepts and theories are generally covered under the umbrella of reader response criticism. Scholars like Louise Rosenblatt, Stanley Fish, Wolfgang Iser, Roland Barthes, Elizabeth Freund, David Bleich and many others have contributed to the development of this theory in which readers cannot be just ignored as passive onlookers. The roots to this theory can be traced back to Louise Rosenblatt's work, Literature as Exploration in 1938 and then it gained importance from the 1960s.

Reading as explained through this theory, can be applied to almost any media which requires perception and sense-making like books, poems, movies, music, paintings, graphic novels, etc. Picture-books have come to be accepted under the popular study of literature in the recent times. This paper aims to revisit and to get a new insight into various nuances of the reading process through an analysis of a well known and applauded picturebook, The Red Tree by Shaun Tan, in the light of the transactional approach proposed by Louise Rosenblatt.

Shaun Tan, an Australian artist, writer and film-maker is very well known for his gripping techniques and approaches to illustrations. His well known works include The Arrival(2006), The Lost thing(2000) and The Red Tree(2001). The Red Tree is a children's picture-book, a very thin volume, which is in fact, apt for a reader of any age, as Tan himself says,

As a concept, the book is inspired by the impulse of children and adults alike to describe feelings using metaphor - monsters, storms, sunshine, rainbows and so on. Moving beyond cliché, I sought painted images that might further explore the expressive possibilities of this kind of shared imagination, which could be at once strange and familiar". ("The Red Tree")

The Red Tree gives a chance to every reader to create his or her own meaning or definition. That's what that makes this picture-book very special as the author himself intended for varied interpretations and understandings: "The Red Tree is a story without any particular narrative; a series of distinct imaginary worlds as self-contained images which invite readers to draw their own meaning in the absence of any written explanation"( Tan, "The Red Tree"). Thus this picture-book and its creation itself promote the reader response theory.

\section{Transactional Approach}

There are many approaches to the reader response theory and one of these is known as the Transactional approach which was popularized by Louise Rosenblatt. According to her, reading is more of a transaction than an interaction as transaction offers a two sided line of action in which both the text and the reader effect each other. This approach doesn't depend on the control of any one element by the other. Through her essay, we come to know that text is not the mere black ink on paper, rather it is what happens when a reader goes through it. Rosenblatt compared transactional way of reading to the electric circuit, in which the positive and negative electrodes remain inert without each other, similarly the reading process would be incomplete without the text or the reader ("Towards a Transactional"44). She confirms and reassures this theory with various psychological experiments related to the process of perception and sense-making.

While going through The Red Tree, one can understand this approach very well as it "is a book without a story"(Tan, "The Red Tree"), so the reader creates the story as he or she looks at the images and the response it generates in them. This response is not passive, rather it is an aware way of looking at the images and to 
understand what triggers their response. The Red Tree has 122 selected words without any punctuation or capital letters which induce the reader to think about them as well as of the images aligned with them. The lack of punctuation can actually be related to our thought process as we don't think with punctuation marks in our mind, rather our thoughts are like snippets starting and ending abruptly. Before starting with the main text of the picture-book, Tan has put an image in the picture-book, which serves as a prologue to the story-less story.

The picture below is layered with the problems of the little girl who appears in the center of all the images in this picture-book: trying to express what she feels but the end result is just letters falling out on the ground with no one understanding them, the background shows her haphazard journey to reach this point in life and yet being unable to do anything at all about this.

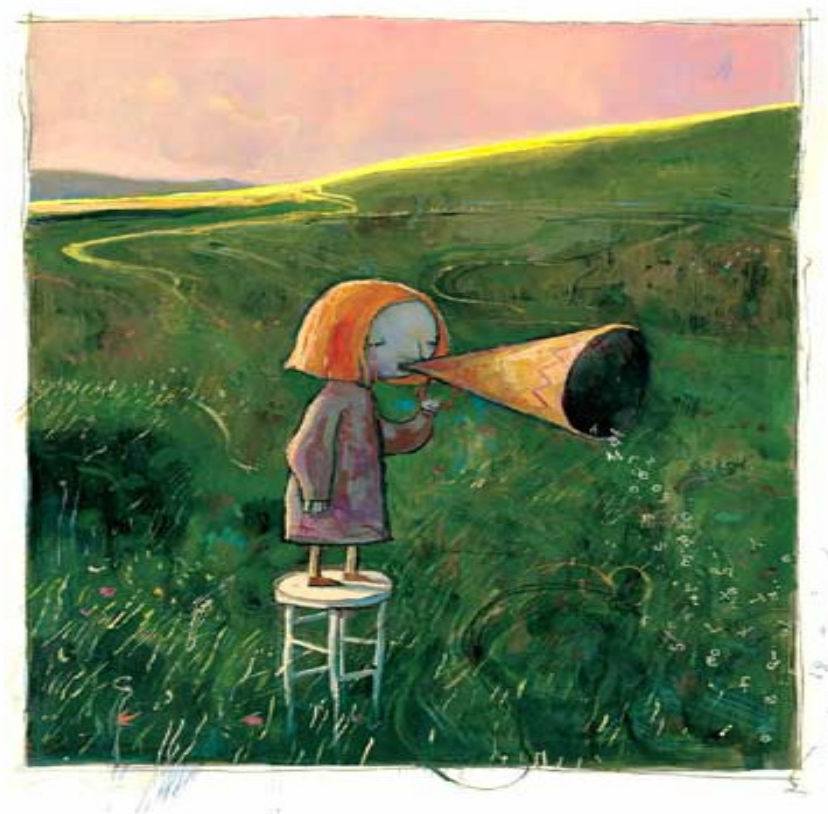

Similarly, the various images in this picture-book as well as the words are just laid out there, for a meaning to be conjured from. Tan clarifies, "It has no sequential narrative, which is something a picture book is ideal for - you can open it at any page, go backwards or forwards, and spend as much time as you wish with each image" ("The Red Tree"). The reading process for this text thus totally depends on the reader as he or she can do whatever they want to it. This is in coherence with Wolfgang Iser's idea of the necessity of gaps in the text which are deliberately left there, so that the reader can fill them from their own experiences and perception (Iser280). He believed that the reader is as important to the text as the author.

\section{Interpretations}

The reader is supposed to have certain responses to the text before even reading it completely according to Rosenblatt, she argues that certain words trigger certain memories or past experiences from the reader's life which helps him or her during the reading process, "Hence my continuing insistence on the idea that the poem is what the reader lives through under the guidance of the text and experiences as relevant to the text"(Rosenblatt,"Towards a transactional"38). This can be understood through looking at the reviews of random readers about The Red Tree on a website:

1. "An absolutely stunning picture book which conveys, in visual language easily accessible to a five year old, what it's like to suffer from a bipolar affective disorder. Move over Sylvia Plath, Tan has done it better."

2. "I completely disagree that this book is about manic depression, which is Manny's take. It is simply about feeling bad and realising that this won't last forever and that things will get better. It is about the irrationality of this process."

3. "2014 has been a crappy year for me. It has. And I'm not complaining, I'm just saying that when I opened this book I was aware of that fact. And it spoke to my heart through words and colors and emotions you can't just express with words."

4. "Brilliant.Words cannot..."

5. "my dear friend carrie gave me this book, little knowing it would speak directly to my heart during a time when my ears didn't seem to be working. powerful stuff in the guise of a children's book."

6. "This story is controversial because it's about sadness. The art is very beautiful like all of Tan's work, 
but the text goes beyond what would be considered an ordinary child's unhappiness and straight on to depression, something the author suffers from."

("The Red tree by Shaun Tan")

These responses to the picture-book give a clear insight into the variety of emotions or memories that a text can evoke in a particular reader at a particular time. These responses are similar as well as different from each other and most probably these random readers don't even know each other. One reader says that this picturebook is about depression yet another reader just denies it outright and puts forward his or her own perception about this picture-book. One of the other readers has just used broken words to explain that words cannot explain the beauty of this picture-book. These different ways of responding to the same text shows how different every individual's perception is. This is known as the "aesthetic reading", in which a reader, "adopts an attitude of readiness to attend to what is being lived through during the reading event" (Rosenblatt, "The Literary Transaction"74). This way of reading can be applied on the text from this picture-book to derive a meaning from bizarre images. For instance, the following image can be analyzed through the existential questions and problems that the little girl is facing.

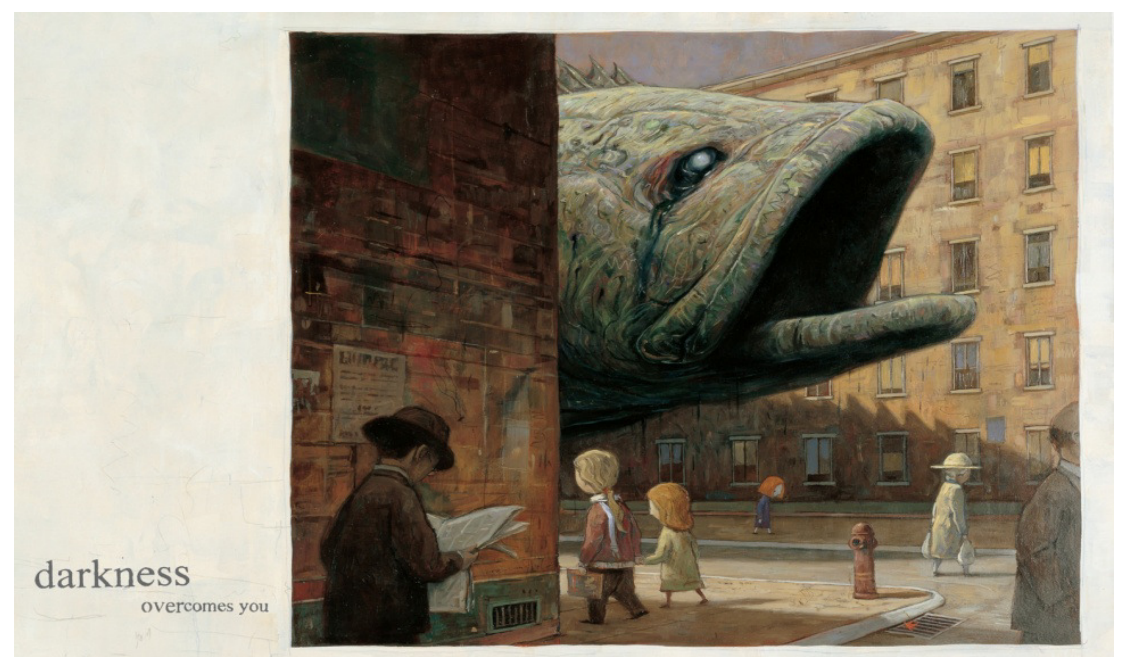

This picture has many aspects to be looked at in order to come at a meaning of it.Juxtaposition and metaphors are used in this image to explain what the girl feels: the giant fish hovering over the little girl can explain how heavy and difficult to manage, our feelings and emotions can sometimes be. The giant fish with bleeding eyes can be took as a metaphor for death and despair and the shadow it is casting over the girl is that of oblivion. Its gaped mouth can express the emptiness and hollowness the little girl might be feeling. She is shown to be very far away in this image as if to tell that she is beyond our help. All the other people in the image are unaware of her and the giant fish. The contrast between the togetherness of the two girls walking hand-in-hand and the alienation of the little girl can be felt through the image. There may be different interpretations to this image for different readers, for instance, a 5 or 6 year old child might just interpret the giant fish as frightening and about to engulf the little girl and this image may be just a fascinating one for him or her. Maybe the same image can evoke different interpretation in a reader when he or she looks at it for a second time under different circumstance. As Rosenblatt stated,

the transaction involving a reader and a printed text thus can be viewed as an event occurring at a particular time in a particular environment at a particular moment in the life history of the reader. The transaction will involve not only the past experience but also the present state and present interests or preoccupations of the reader. It stresses the possibility that printed marks on a page will become different linguistic symbols by virtue of transactions with different readers. ("Towards a Transactional"45)

This shows that reading is not a static task rather it is an ongoing dynamic process which keeps changing with the reader and the context too. Transactional way of reading can thus be understood through the dynamism of reading, which is in continuum rather than a fixed concept. Even the author himself who is supposed to be the first reader, might have different interpretations of it at a different point of time when he or she has a different relationship with the text (Rosenblatt, "Towards a Transactional"35). Shaun Tan talks about it in a similar light keeping in mind that he is the author, "It's not as if the book is a puzzle punctuated by clues, that needs to be solved. Unlike a riddle, there is no clear answer to these questions, which remain open. I myself continue to find new meanings in the words and pictures as I did when producing the story over the course of a year" ("PICTURE BOOKS")

The Red Tree has very few words accompanying the pictures, these words are there to say something, but 
never too much and never referring to the content in any literal or conceptual way so that these words won't hinder the mysterious invitation forwarded to the readers while looking at each image. Phrases like " darkness overcomes you", "nobody understands" and "without sense or reason" all conjure up different images in our minds especially combined with the images they are accompanied with in the picture-book. For instance, the word 'dog' does have a specific meaning according to nomenclature and the dictionary, yet different people perceive it as different: a person who loves dogs might associate the word with love, affection and companionship and at the same time, a person who has been bit by a dog might associate the same word with fear and pain.

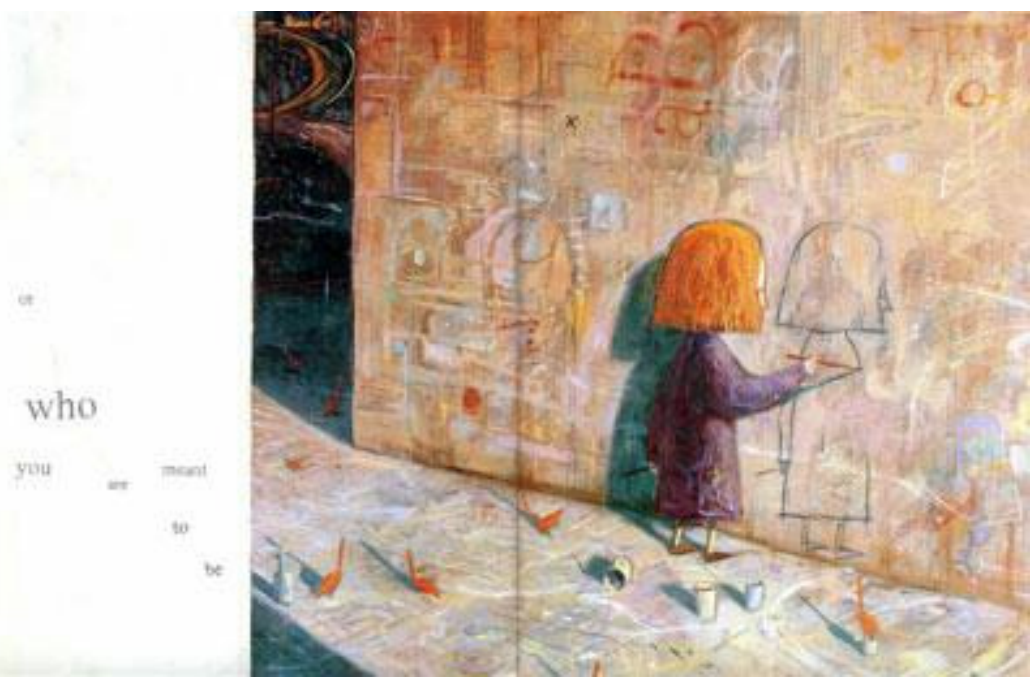

This explains the difference in the images conjured by different people in their minds. There are existential thoughts in this picture-book which might generate different thoughts in different people, for instance, theimage on the last page, of the little girl drawing herself on the wall and the words accompanying the image, "or who you are meant to be". For example, a little child can perceive that image as an attempt to search for a sense of belonging or to fit in, whereas a philosophy student might relate the image with the teachings of Socrates, Camus and Sartre. In the same way, an old person who is left alone in a house by himself might relate that same image to his loneliness and worthlessness of life and hard-work.

The reading of this picture-book also demands special attention to the visual interpretation of not just the symbols and metaphors but also the ways that the different images have been illustrated. There's an image with the little girl standing in the center with the words "world is a deaf machine" and the image is drawn from a low angle which makes the pillars of the deaf machine to appear larger than lie and menacing. The costuming in this image points towards the conformity that the world expects from everyone and the locked away light bulb shows the little girl's individuality. The colours used in the images in also very important, like the red coloured leaf which is a motif in the this picture-book. The red colour stands for its symbolic meanings like passion, danger and draws the reader's attention to it. The image of two colliding ships in a storm with the little girl in a small life-boat near a whirlpool induces a special effect on the reader through the whirlpool like image which somehow sucks everything into it and the words on the image, "then all your problems come at once" intensifies the effect. The image with eight frames starting with a close-up shot and then ending with a far away shot creates an effect of alienation that the little girl feels while waiting and the words on the last frame, "but nothing ever happens" describe her utter disillusionment. 

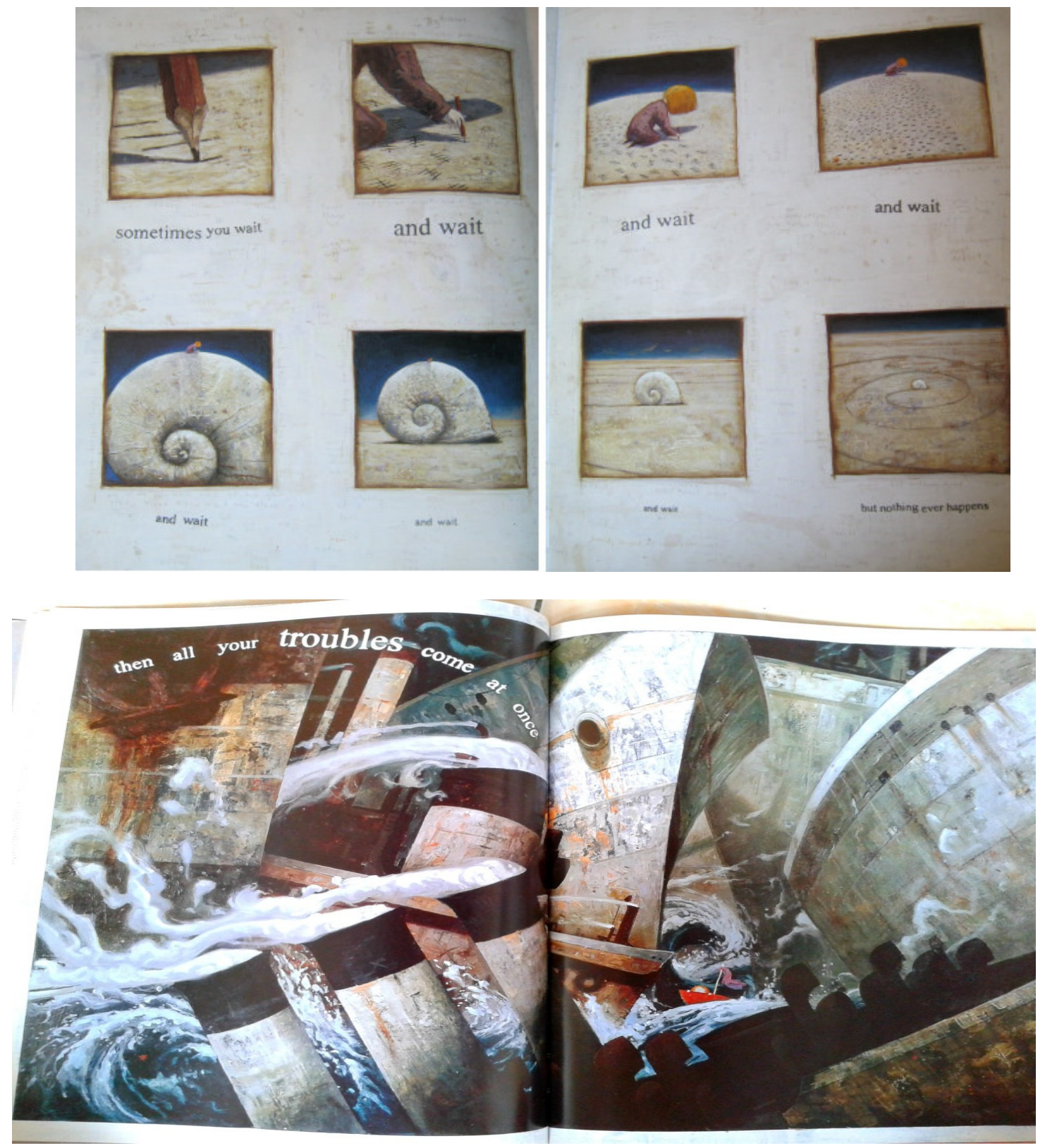

The visual effects that this picture-book evoke, can be studied through individual images or the picturebook as a whole. The girl's journey is shown to be a cyclical one as it ends where it began- her bedroom. There are many approaches to go about as to interpret this picture-book through a variety of lenses.

\section{Conclusion}

This paper has tried to describe some of these lenses or approaches in order to explain the complexity of reading process while keeping in mind that the picture-book used to demonstrate this complexity is actually categorized under children's literature. This shows that even a small picture-book intended for young kids can have so many meanings and so many different methods to interpret its various aspects. Rosenblatt's transactional approach and the aesthetic way of reading has helped to

re-create many meanings of the images in this picture-book. Reading therefore is not just a simple process where one just keeps on passively going through the pages, rather it is a process where the reader plays an active role in co-creating as well as re-creating many meanings of the text. The reader response theory can thus be understood not just as a major breakthrough in the world of literary theory, in fact, it is fundamental to the basic process of perception and interpretation.

\section{References}

Iser, Wolfgang. (1974). "The Reading Process: A Phenomenological Approach".WolfgangIser,. The implied reader: patterns of communication in prose fiction from Bunyan to Beckett. Baltimore: Johns Hopkins 
University Press,( pp.274-294).

Rosenblatt, Louise. (1986). "The Literary Transaction." The Creating Word,66-85

Rosenblatt, Louise.(1969)."Towards a Transactional Theory of Reading." Journal of Literacy Research 1.1,3149

Tan, Shaun.(2017). "PICTURE BOOKS: Who Are They For?" Comments. N.p., n.d. Web. 25 Apr. 2017

Tan, Shaun. (2017). "The Red Tree." Picture Books. N.p., n.d. Web. 25 Apr. 2017

Tan, Shaun.(2014). The Red Tree. Sydney, NSW: Hatchette, Australia, Pty Limited.

"The Red Tree by Shaun Tan." Rev. of The Red Tree. N.p., n.d.Goodreads. Web. 25 Apr. 2017. 